\title{
Lowering Corticosterone Levels Reinstates Hippocampal Brain-Derived Neurotropic Factor and Trkb Expression without Influencing Deficits in Hypothalamic Brain-Derived Neurotropic Factor Expression in Leptin Receptor-Deficient Mice
}

\author{
Alexis M. Stranahan ${ }^{a, b}$ Thiruma V. Arumugam ${ }^{b}$ Mark P. Mattson ${ }^{b}$ \\ ${ }^{a}$ Department of Psychological and Brain Sciences, Johns Hopkins University, and ${ }^{b}$ Cellular and Molecular \\ Neuroscience Section, Laboratory of Neurosciences, National Institute on Aging, Baltimore, Md., USA
}

\section{Key Words}

Diabetes $\cdot$ Glucocorticoid $\cdot$ Neurotropic factor .

Hippocampus $\cdot$ Hypothalamus

\begin{abstract}
Background/Aims: Changes in the glucocorticoid milieu contribute to alterations in neurotropic factor expression across multiple brain regions. Insulin-resistant diabetes is often accompanied by dysregulation of adrenal steroid production in humans and animal models. Leptin receptor-deficient mice $(d b / d b)$ show reduced expression of brain-derived neurotropic factor (BDNF) in the hippocampus and increases in circulating corticosterone levels, but the extent to which elevated corticosterone levels mediate deficits in BDNF expression has not been determined. Methods: Using in situ hybridization, we measured the expression of BDNF, its receptor TrkB, and neurotropin-3 (NT-3) in the hippocampus and hypothalamus of $d b / d b$ mice and wild-type controls following adrenalectomy and low-dose corticosterone replacement (ADX+CORT) or sham operation. Results: Lowering corticosterone levels restored BDNF and TrkB expression in the hippocampus of $d b / d b$ mice. However, deficits in hypothalamic BDNF expression were not reversed following $A D X+C O R T$. There was no effect of genotype or adrenalec-
\end{abstract}

\section{KARGER}

Fax +4161306 1234

E-Mail karger@karger.ch

www.karger.com (c) 2010 S. Karger AG, Basel

Accessible online at:

www.karger.com/nen tomy on NT-3 expression in any brain region examined. Conclusion: Leptin receptor-deficient mice exhibit reduced BDNF expression in the hippocampus and hypothalamus. In the $d b / d b$ mouse hippocampus, suppression of BDNF occurs in a glucocorticoid-dependent fashion, while hypothalamic BDNF expression is reduced via glucocorticoid-independent mechanisms. Region-specific signals therefore play a role in the interaction between corticosteroids and neurotropic factor expression.

Copyright $\odot 2010$ S. Karger AG, Basel

Diabetes is associated with synaptic rearrangement across multiple brain regions [1-3]. One commonly used animal model of insulin-resistant diabetes is the $d b / d b$ mouse, which lacks functional leptin receptors. $d b / d b$ mice are obese, with elevated glucose and insulin levels and reduced insulin sensitivity [4]. $d b / d b$ mice also exhibit increased levels of corticosterone, the primary stress-responsive hormone in rodents [1]. In nondiabetic rodents, exposure to elevated corticosterone levels reduces the expression of neurotropic factors that support synaptic plasticity, such as brain-derived neurotropic factor (BDNF) [4]. $d b / d b$ mice also exhibit reductions in hippocampal BDNF expression [1], but the question of whether 
elevated corticosterone levels mediate the impairment of hippocampal BDNF expression in $d b / d b$ mice has not been addressed.

While hippocampal BDNF signaling is closely associated with synaptic plasticity mechanisms that contribute to learning, hypothalamic neurotropin expression regulates feeding, metabolism, and stress. Selective reductions in BDNF in the hypothalamus induce hyperphagia in rodent models [6], as does chronic administration of high levels of corticosterone [7]. $d b / d b$ mice are hyperphagic, and activating the BDNF receptor TrkB in the hypothalamus counteracts this aspect of their phenotype [8]. Central administration of BDNF also enhances glucose metabolism in $d b / d b$ mice [9] and promotes energy expenditure [10]. However, the possible regulation of endogenous hypothalamic neurotropin expression by elevated corticosterone levels in $d b / d b$ mice remains unexplored.

To determine whether hippocampal and hypothalamic neurotropin levels might be under the control of corticosteroids in $d b / d b$ mice, we measured expression of BDNF, its high-affinity receptor $\operatorname{TrkB}$, and neurotropin-3 (NT-3) following adrenalectomy and low-dose corticosterone replacement $(\mathrm{ADX}+\mathrm{CORT})$. We observed that lowering corticosterone levels reversed deficits in BDNF and $\operatorname{TrkB}$ expression in the hippocampus. $d b / d b$ mice also exhibit reduced hypothalamic BDNF expression, but this was not attributable to changes in levels of corticosterone. This suggests that a region-specific suppression of hippocampal BDNF and TrkB expression occurs following exposure to chronically elevated corticosterone levels in diabetic mice.

\section{Methods}

Animals, Food Intake, and Surgery

Animal care and experimental procedures followed National Institutes of Health guidelines and were approved by the National Institute on Aging Animal Care and Use Committee. Food intake and body weights were monitored weekly throughout the experiment. Male mice mutant for the leptin receptor $(d b / d b$ mice), bred on a C57BL/6 background, were purchased from Jackson Laboratories. Age-matched male C57BL/6 mice were used as controls. Mice were subjected to bilateral ADX+CORT or sham operation at postnatal day 30 . ADX+CORT mice received corticosterone replacement $(25 \mu \mathrm{g} / \mathrm{ml}$ in $0.9 \%$ saline; Sigma) via their drinking water as described [11].

\section{Serum Measurements}

Completeness of adrenalectomy was verified with radioimmunoassay for serum corticosterone using a commercially available kit as described in Stranahan et al. [11]. Glucose levels were measured following an overnight fast using a Therasense handheld analyzer (Therasense, Alameda, Calif., USA) according to previously published protocols [1]. Insulin levels in serum were quantified using ELISA (Crystal Chem, Downers Grove, Ill., USA) following standard methodology as described [1] and the plates were read at $490 \mathrm{~nm}$ on an automatic plate reader (Perkin Elmer HTS 7,000 Plus Bio Assay Reader, Perkin Elmer, Waltham, Mass., USA).

\section{Tissue Preparation}

Mice were perfused transcardially with $4 \%$ paraformaldehyde in phosphate-buffered saline under deep isoflurane anesthesia. Brains were postfixed in $4 \%$ paraformaldehyde with progressively increasing concentrations of sucrose, and then stored at $-80^{\circ} \mathrm{C}$ prior to sectioning. Hemi-brains were sectioned at $40 \mu \mathrm{m}$ on the coronal plane using a freezing microtome. Sections were collected in a 1:6 series and stored in 4\% paraformaldehyde in preparation for in situ hybridization.

\section{In situ Probe Generation}

Generation of riboprobes for in situ hybridization was performed as described in Stranahan et al. [12]. Probe sequences were as follows: for BDNF, right primer gtctgacgacgacatcactg, left primer ccatgggattacacttggtc; for TrkB, right primer acaagctgacgagtttgtcc, left primer cttaaggagccctgtgtgtg; for NT-3, right primer ggcaacagagacgctacaat, left primer agtcagtgctcggacatagg.

\section{In situ Hybridization and Image Analysis}

In situ hybridization was carried out as described [12]. We performed densitometric analysis on scanned images from a phosphoimager screen. Regions of interest from five matched sections throughout the dorsal hippocampus, dorsomedial hypothalamus, or ventromedial hypothalamus were hand-drawn using ImageQuant (GE Healthcare) by an experimenter blind to group conditions. Sections were averaged to obtain a single score for each animal and anatomical boundaries were made with reference to the atlas of Paxinos and Franklin [13].

\section{Statistics}

In situ hybridization and serum data were compared across genotypes and surgical conditions using two-way ANOVA with Tukey's post hoc using Graphpad Prism (Graphpad, La Jolla, Calif., USA). Body weights and food intake were analyzed using two-way repeated-measures ANOVA in SPSS version 18.0 (IBM, Somers, N.Y., USA). For all analyses, statistical significance was set at $\mathrm{p}<0.05$.

\section{Results}

\section{Effects of Lowering Corticosterone Levels on Weight}

Gain and Food Intake in $\mathrm{db} / \mathrm{db}$ Mice

Leptin receptor deficiency increased body weights in both adrenally intact and adrenalectomized $d b / d b$ mice receiving corticosterone replacement (ADX+CORT; fig. 1a; for the interaction between genotype and surgery, $\mathrm{F}_{1,31}=$ $21.98, \mathrm{p}<0.001)$. In terms of energy intake, $d b / d b$ mice ate more than wild-type mice, consistently, throughout the experiment (fig. $1 \mathrm{~b}$; for the effect of genotype, $\mathrm{F}_{1,37}=56.30$, $\mathrm{p}<0.001)$. 

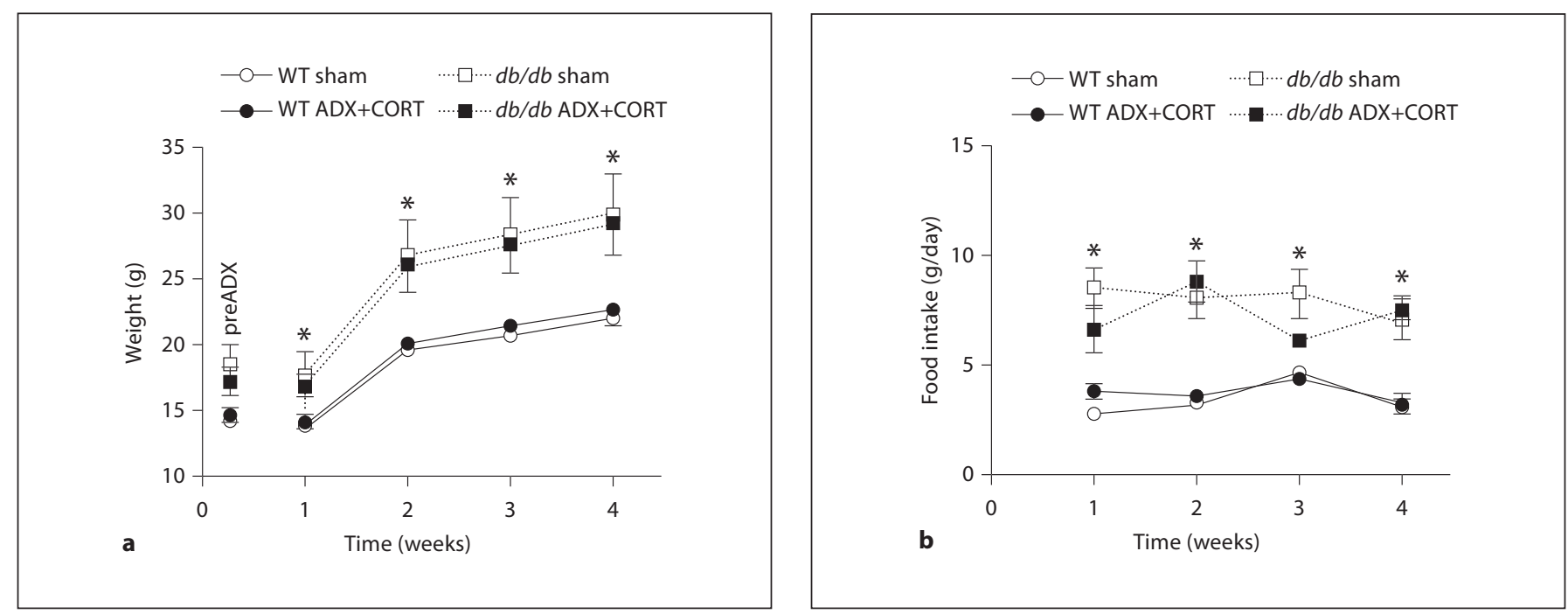

Fig. 1. Similarly elevated body weights and increased food intake in $d b / d b$ mice with different levels of corticosterone. a Both sham-operated and ADX+CORT $d b / d b$ mice weigh more than wild-type mice. $\mathbf{b} d b / d b$ mice consumed more food than wild-type mice, without respect to corticosteroid status. ${ }^{*}$ Significance at $\mathrm{p}<0.05$ following two-way repeated-measures ANOVA.

\section{Lowering Corticosterone Levels Attenuates Some Features of Endocrine Pathology in Leptin Receptor-Deficient Mice}

A number of neuronally relevant hormones and gut peptides are dysregulated in $d b / d b$ mice, but we chose to focus on glucose, insulin, and corticosterone to characterize basic features of glucoregulation in the context of changes in stress hormones. Consistent with our previous study [11], lowering corticosterone levels normalizes fasting glucose levels in serum from $d b / d b$ mice in the current experiment (fig. 2; $\mathrm{F}_{1,20}=61.62$, $\mathrm{p}<0.001$ ). ADX+ CORT also attenuated hyperinsulinemia (fig. $2 ; \mathrm{F}_{1,23}=$ $3.38, \mathrm{p}=0.048)$. In further support of earlier observations, $d b / d b$ mice have elevated levels of circulating corticosterone (fig. $2 ; \mathrm{F}_{1,22}=16.70, \mathrm{p}=0.003$ ), which was reduced through ADX+CORT.

\section{Lowering Corticosterone Levels Selectively Restores}

Dentate Gyrus BDNF Expression in $\mathrm{db} / \mathrm{db}$ Mice

To look at expression of a gene that has been implicated in both metabolism [14] and synaptic plasticity [15], we measured BDNF expression using in situ hybridization. BDNF mRNA expression is reduced in the hippocampal dentate gyrus of adrenally intact $d b / d b$ mice $\left(\mathrm{F}_{1,20}=15.22, \mathrm{p}=0.009\right.$; fig. 3b, 4a). ADX+CORT restored dentate gyrus BDNF expression in $d b / d b$ mice $\left(\mathrm{F}_{1,20}=\right.$ $6.86, \mathrm{p}=0.018)$. There was no significant effect of genotype on BDNF levels in hippocampal area CA3 $\left(\mathrm{F}_{1,20}=\right.$

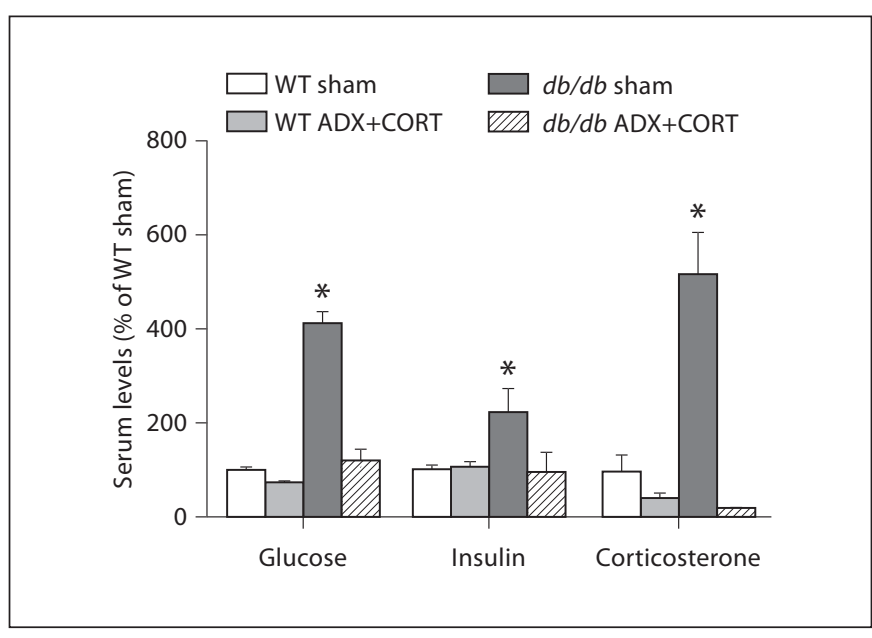

Fig. 2. Lowering corticosterone levels ameliorates hyperglycemia and attenuates elevations in circulating insulin levels in $d b / d b$ mice. Glucose and insulin levels reflect serum concentrations following an overnight fast. Corticosterone levels were measured in serum taken from cardiac blood before perfusion under isoflurane anesthesia; elapsed time from initial cage disturbance to collection of blood samples was $<3 \mathrm{~min}$. ${ }^{*}$ Significant difference following two-way ANOVA.

$0.28, \mathrm{p}=0.60)$ or CA1 $\left(\mathrm{F}_{1,20}=0.01, \mathrm{p}=0.92\right)$. There was also no change in $\mathrm{BDNF}$ levels following $\mathrm{ADX}+\mathrm{CORT}$ in hippocampal area CA3 $\left(\mathrm{F}_{1,20}=1.69, \mathrm{p}=0.21\right)$ or CA1 $\left(\mathrm{F}_{1,20}=2.07, \mathrm{p}=0.16\right)$. 
Fig. 3. Differential regulation of BDNF and its receptor TrkB by corticosterone in the hypothalamus and hippocampus of $d b / d b$ mice. a BDNF mRNA expression is reduced in the dorsomedial (DMH) and ventromedial $(\mathrm{VMH})$ hypothalamus of $d b / d b$ mice irrespective of corticosteroid status. Boxed area on autoradiographic images shown as a heat map in the inset. b Hippocampal BDNF expression is impaired in adrenally intact $d b / d b$ mice, but not in $d b / d b$ mice that received ADX+ CORT. For $\mathbf{a}, \mathbf{b}$, the probe targets the genomic region common to all transcript variants of the BDNF gene. c Hippocampal TrkB expression levels are similarly compromised in sham-operated $d b / d b$ mice, and this can be prevented by lowering the levels of corticosterone. For a-c, there was no effect of ADX+CORT on expression of either BDNF or TrkB in wild-type mice.

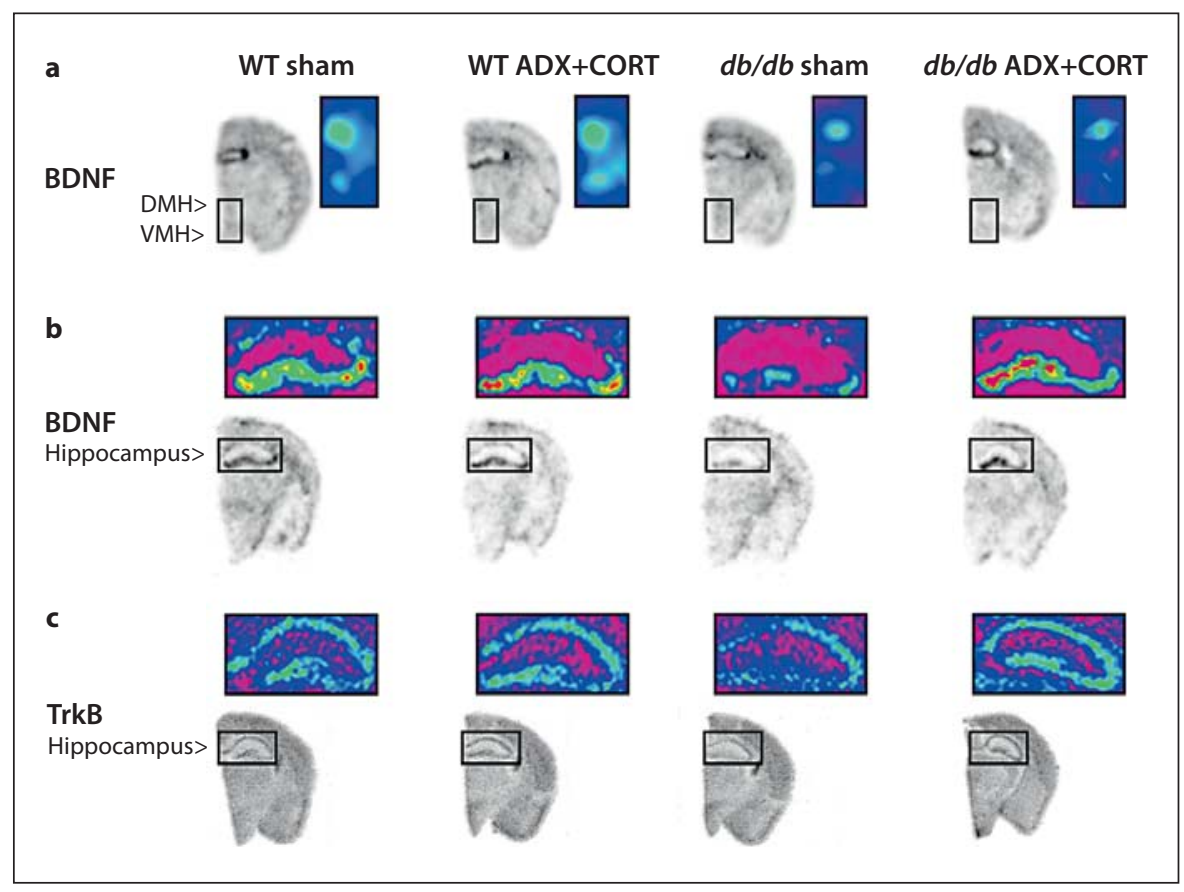

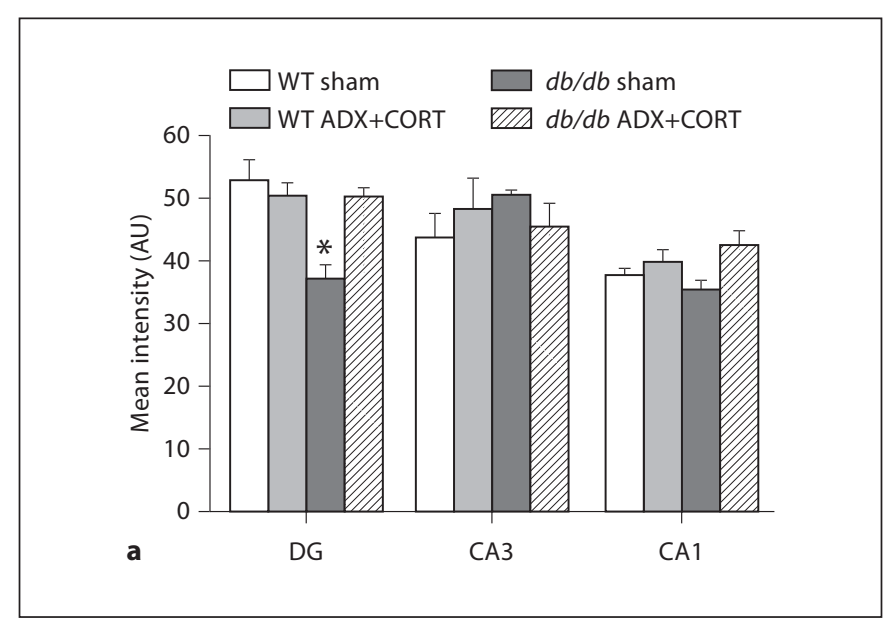

Fig. 4. Densitometric quantification of BDNF expression in the hippocampus and hypothalamus of $d b / d b$ and wild-type mice with different levels of corticosterone. a Within the hippocampus, sham-operated $d b / d b$ mice have lower BDNF expression, specifically in the dentate gyrus subfield, where impairments in dendritic spine density [1] and synaptic plasticity [9] have also been observed. $d b / d b$ mice that received ADX+CORT show no deficit

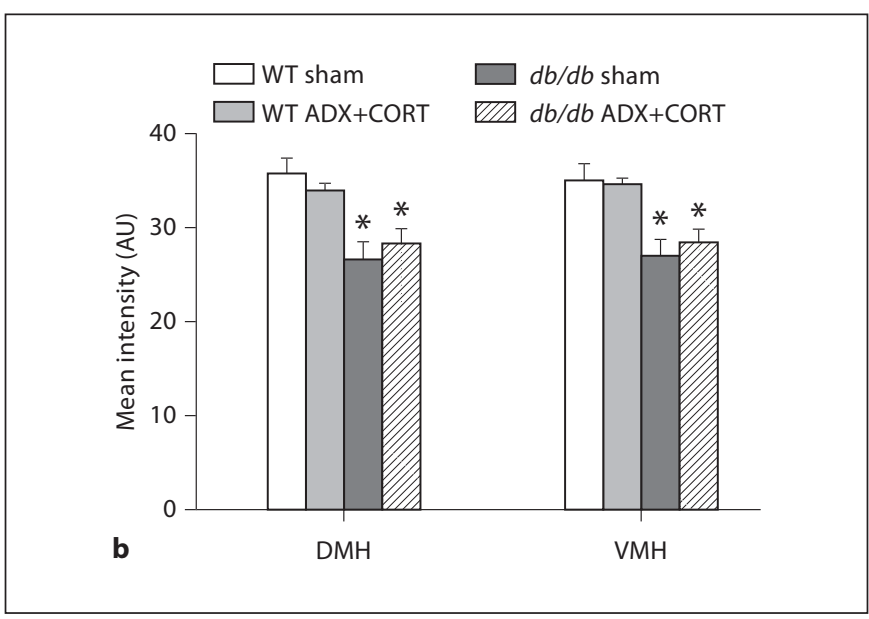

in BDNF expression. $\mathbf{b}$ In the dorsomedial (DMH) and ventromedial (VMH) nuclei of the hypothalamus, $d b / d b$ mice exhibit reduced BDNF mRNA expression, irrespective of glucocorticoid status. There was no effect of ADX+CORT on hippocampal or hypothalamic BDNF expression in wild-type mice. ${ }^{*}$ Significance at $\mathrm{p}<0.05$ following two-way ANOVA. $d b / d b$ mice exhibit reduced BDNF expression in the dorsomedial and ventromedial nuclei of the hypothalamus (DMH and VMH), two regions where BDNF signaling negatively regulates feeding behavior [8]. However, impairment of hypothalamic BDNF expression occurred in both adrenally intact $d b / d b$ mice, and in $d b / d b$ mice subject to $\mathrm{ADX}+\mathrm{CORT}$ (fig. $3 \mathrm{a}, 4 \mathrm{~b} ; \mathrm{DMH}, \mathrm{F}_{1,20}=23.05$, $\left.\mathrm{p}=0.001 ; \mathrm{VMH}, \mathrm{F}_{1,20}=19.6, \mathrm{p}=0.003\right)$. Insofar as BDNF 

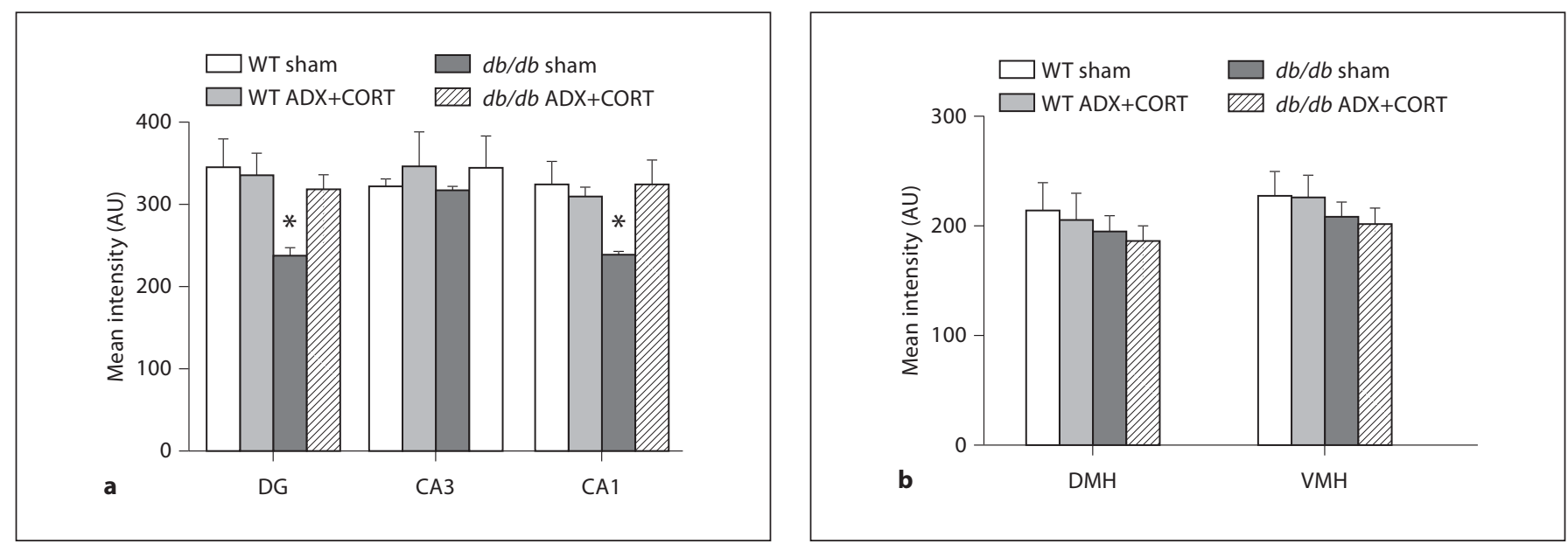

Fig. 5. Glucocorticoid-dependent changes in TrkB expression in leptin receptor-deficient mice are restricted to the hippocampus. a Adrenally intact $d b / d b$ mice have lower levels of TrkB mRNA, specifically in the hippocampal dentate gyrus (DG) and CA1 subfields. This deficit was not observed in $d b / d b$ mice that received ADX+CORT. * Significance at $\mathrm{p}<0.05$ following two-way ANOVA. b In the dorsomedial (DMH) and ventromedial (VMH) nuclei of the hypothalamus, no changes in TrkB expression were detected.

expression in the DMH and VMH can be viewed as an inverse correlate for food intake, this is consistent with our observation that ADX+CORT does not influence hyperphagia in $d b / d b$ mice (fig. $1 b$ ).

Reinstatement of Normal Physiological Corticosterone Levels Restores TrkB Expression in the $\mathrm{db} / \mathrm{db}$ Mouse Hippocampus

Adrenally intact $d b / d b$ mice show reduced expression of TrkB mRNA in the dentate gyrus (fig. 3c, 5a; DG, $\left.\mathrm{F}_{1,20}=13.52, \mathrm{p}=0.001\right)$ and CA1 subfields $\left(\mathrm{F}_{1,20}=6.41\right.$, $\mathrm{p}=0.02)$. There was no significant effect of genotype on TrkB expression in the CA3 subfield $\left(\mathrm{F}_{1,20}=1.69, \mathrm{p}=\right.$ $0.21) . d b / d b$ mice that received ADX+CORT had levels of TrkB that were indistinguishable from wild-type mice, suggesting that chronic exposure to elevated corticosterone levels impairs TrkB expression in the $d b / d b$ mouse hippocampus. By contrast, TrkB expression in the DMH (fig. 5b; $\left.\mathrm{F}_{1,16}=0.19, \mathrm{p}=0.67\right)$ and $\mathrm{VMH}\left(\mathrm{F}_{1,16}=1.62\right.$, $\mathrm{p}=0.22$ ) was not influenced by either genotype or ADX+CORT, suggesting that the effect of elevated corticosterone levels on TrkB expression in $d b / d b$ mice may be region-specific.

\section{NT-3 mRNA Expression Is Not Affected by Genotype or Surgery}

To determine whether elevated corticosterone levels globally downregulate neurotropin expression, we also quantified levels of NT-3, a neurotropin that activates TrkC, a different but closely related receptor. There was no effect of genotype on NT-3 mRNA levels in the dentate gyrus (fig. $\left.6 \mathrm{a} ; \mathrm{F}_{1,16}=2.54, \mathrm{p}=0.13\right), \mathrm{CA} 3\left(\mathrm{~F}_{1,16}=1.96, \mathrm{p}=\right.$ $0.18)$, or CA1 subfield $\left(\mathrm{F}_{1,16}=1.16, \mathrm{p}=0.29\right)$ of the hippocampus (fig. 1a, d). Likewise, there was no effect of genotype or adrenalectomy on NT-3 expression in the DMH (fig. $\left.6 \mathrm{~b} ; \mathrm{F}_{1,16}=0.02, \mathrm{p}=0.87\right)$ or $\mathrm{VMH}\left(\mathrm{F}_{1,16}=0.89, \mathrm{p}=\right.$ $0.35)$.

\section{Discussion}

We have observed differential regulation of BDNF expression by corticosterone in the hippocampus and hypothalamus of $d b / d b$ mice. Within the hippocampus, lowering corticosterone levels reinstated normal BDNF and TrkB mRNA expression in $d b / d b$ mice. There were no changes in NT-3, suggesting that alterations in neurotropin signaling may be specific to BDNF and its receptor.

In the hypothalamus, both adrenally intact and adrenalectomized $d b / d b$ mice receiving corticosterone replacement exhibit reduced BDNF expression. This anatomical pattern supports a distinct role for corticosteroids in the suppression of hippocampal, but not hypothalamic, BDNF expression in $d b / d b$ mice.

Glucocorticoid receptor (GR) activation mediates corticosterone-induced downregulation of BDNF mRNA 

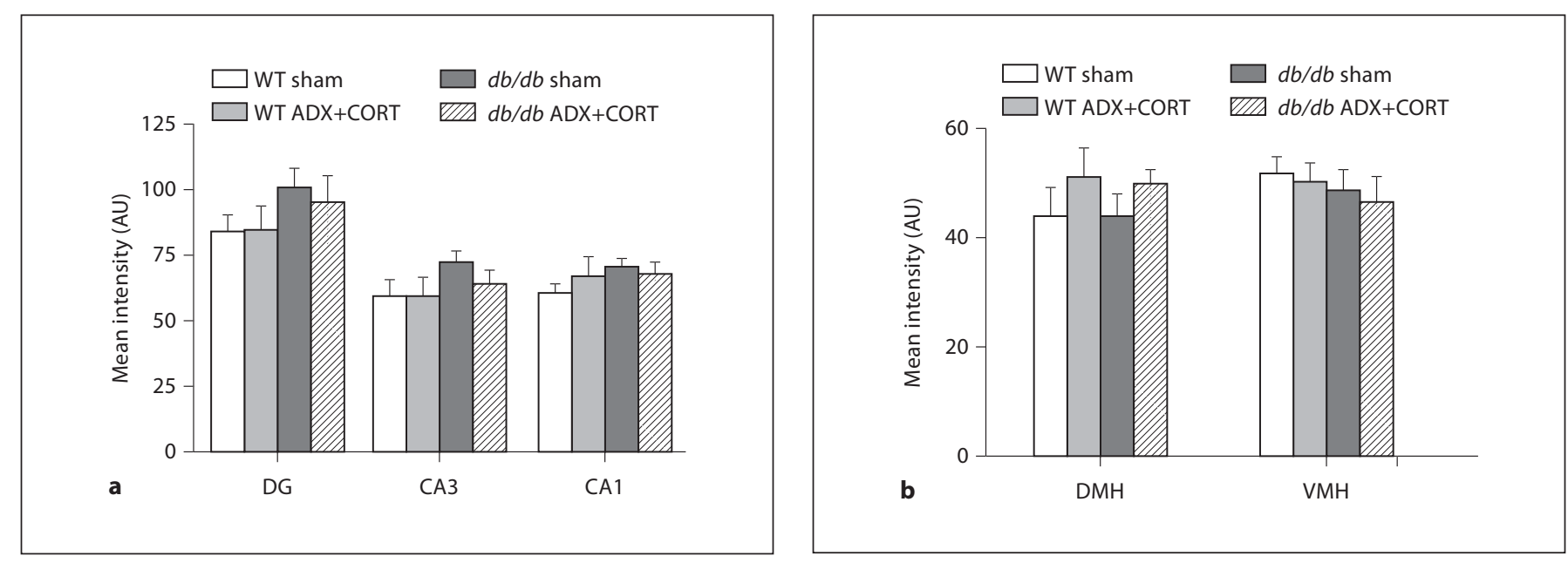

Fig. 6. NT-3 expression is unchanged in leptin receptor-deficient mice. a Hippocampal NT-3 expression was not significantly altered by either genotype or surgical condition in any subfield. b NT-3 expression in the dorsomedial (DMH) and ventromedial (VMH) nuclei of the hypothalamus is unaffected by genotype or surgery.

expression in the hippocampus [16]. The hippocampus and hypothalamus differ in their relative levels of GR expression. In mice, the hippocampus expresses GR at higher levels, relative to the hypothalamus [17]. Hippocampal BDNF gene transcription is reduced via corticosterone-dependent mechanisms in leptin receptor-deficient mice, while reductions in hypothalamic BDNF are not attributable to changes in levels of corticosterone. It is possible that differential regulation of BDNF by corticosterone in the hippocampus and hypothalamus could be related to the different concentrations of GR in these two regions. Alternately, BDNF participates in many molecular pathways, and perturbations across one or more other pathways could downregulate hypothalamic BDNF independently of GR in the hypothalamus.

$d b / d b$ mice lack functional leptin receptors, and this signaling pathway may be a potential mediator for effects on neuronal gene expression in the hippocampus and hypothalamus. Leptin activates its canonical JAK/STAT pathway to promote sensations of satiety in the hypothalamus [18], and in the hippocampus, leptin enhances forms of synaptic plasticity that are thought to underlie learning [19]. While treatment with leptin enhances hypothalamic BDNF in normal mice [20], there is no mechanistic data to suggest that the converse is true: namely, that loss of leptin signaling or sensitivity impairs hypothalamic BDNF expression. Likewise, in the hippocampus, although leptin application regulates glutamate receptor trafficking [21] and long-term potentiation [19], no studies exist to determine whether there is a direct link between leptin and BDNF expression. In the current study, lowering corticosterone levels does not change the mutation that renders the leptin receptor inactive in $d b /$ $d b$ mice, so any changes are unlikely to be attributable to alterations in leptin receptor signaling.

$d b / d b$ mice exhibit chronically elevated adrenal steroid hormone levels [11]. This leads to greater cumulative exposure of neurons to the consequences of corticosteroid-mediated changes in gene transcription. In the hippocampus, these changes may relate to the impairment of learning and memory [11]. In the hypothalamus, corticosteroid-independent changes in neurotropic factor expression could alter functional plasticity among circuits associated with energy expenditure, food intake, and metabolism. Targeted restoration of neurotropic factor expression - to the hippocampus, with the idea of reinstating learning, or to the hypothalamus, with the goal of normalizing energy balance - will be a fruitful avenue for future study.

\section{Acknowledgements}

This work was supported by a Ford Foundation Fellowship to A.M.S., and by the National Institute on Aging Intramural Research Program. We are grateful to Rebecca Haberman for insightful suggestions and Michela Gallagher for use of resources for the in situ hybridization experiments. 


\section{References}

1 Stranahan AM, Lee K, Martin B, Maudsley S, Golden E, Cutler RG, Mattson MP: Voluntary exercise and caloric restriction enhance hippocampal dendritic spine density and BDNF levels in diabetic mice. Hippocampus 2009;19:951-961.

-2 Stranahan AM, Norman ED, Lee K, Cutler RG, Telljohann RS, Egan JM, Mattson MP: Diet-induced insulin resistance impairs hippocampal synaptic plasticity and cognition in middle-aged rats. Hippocampus 2008;18: 1085-1088.

$>3$ Hernández-Fonseca JP, Rincón J, Pedreañez A, Viera N, Arcaya JL, Carrizo E, Mosquera J: Structural and ultrastructural analysis of cerebral cortex, cerebellum, and hypothalamus from diabetic rats. Exp Diabetes Res 2009;2009:329632.

4 Hummel KP, Dickie MM, Coleman DL: Diabetes, a new mutation in the mouse. Science 1966;153:1127-1128.

$>5$ Schaaf MJ, de Jong J, de Kloet ER, Vreugdenhil E: Downregulation of BDNF mRNA and protein in the rat hippocampus by corticosterone. Brain Res 1998;813:112-120.

$\checkmark 6$ Unger TJ, Calderon GA, Bradley LC, SenaEsteves M, Rios M: Selective deletion of BDNF in the ventromedial and dorsomedial hypothalamus of adult mice results in hyperphagic behavior and obesity. J Neurosci 2007;27:14265-14274.

$>7$ Karatsoreos IN, Bhagat SM, Bowles NP, Weil ZM, Pfaff DW, McEwen BS: Endocrine and physiological changes in response to chronic corticosterone: a potential model of the metabolic syndrome in mouse. Endocrinology 2010;151:2117-2127.
8 Tsao D, Thomsen HK, Chou J, Stratton J, Hagen M, Loo C, Garcia C, Sloane DL, Rosenthal A, Lin JC: TrkB agonists ameliorate obesity and associated metabolic conditions in mice. Endocrinology 2008;149:1038-1048.

$\checkmark 9$ Nakagawa T, Tsuchida A, Itakura Y, Nonomura T, Ono M, Hirota F, Inoue T, Nakayama C, Taiji M, Noguchi H: Brain-derived neurotrophic factor regulates glucose me tabolism by modulating energy balance in diabetic mice. Diabetes 2000;49:436-444.

10 Nonomura T, Tsuchida A, Ono-Kishino M, Nakagawa T, Taiji M, Noguchi H: Brain-derived neurotrophic factor regulates energy expenditure through the central nervous system in obese diabetic mice. Int J Exp Diabetes Res 2001;2:201-209.

-11 Stranahan AM, Arumugam TV, Cutler RG, Lee K, Egan JM, Mattson MP: Diabetes impairs hippocampal function through glucocorticoid-mediated effects on new and mature neurons. Nat Neurosci 2008;11:309-317.

12 Stranahan AM, Haberman RP, Gallagher M: Cognitive decline is associated with reduced reelin expression in the entorhinal cortex of aged rats. Cerebral Cortex 2010 June 10 [Epub ahead of print].

13 Paxinos G, Franklin KBJ: The Mouse Brain in Stereotaxic Coordinates, ed 2. San Diego, Academic Press, 2001.
14 Burkhalter J, Fiumelli H, Allaman I, Chatton JY, Martin JL: Brain-derived neurotrophic factor stimulates energy metabolism in developing cortical neurons. J Neurosci 2003; 23:8212-8220.

15 Minichiello L: TrkB signalling pathways in LTP and learning. Nat Rev Neurosci 2009; 10: 850-860.

16 Hansson AC, Sommer W, Rimondini R, Andbjer B, Strömberg I, Fuxe K: c-fos reduces corticosterone-mediated effects on neurotrophic factor expression in the rat hippocampal CA1 region. J Neurosci 2003;23. 6013-6022.

17 Pryce CR: Postnatal ontogeny of expression of the corticosteroid receptor genes in mammalian brains: inter-species and intra-species differences. Brain Res Rev 2008;57:596605 .

18 Ahima RS, Qi Y, Singhal NS: Adipokines that link obesity and diabetes to the hypothalamus. Prog Brain Res 2006;153:155-174.

19 Shanley LJ, Irving AJ, Harvey J: Leptin enhances NMDA receptor function and modulates hippocampal synaptic plasticity. J Neurosci 2001;21:RC186.

20 Komori T, Morikawa Y, Nanjo K, Senba E: Induction of brain-derived neurotrophic factor by leptin in the ventromedial hypothalamus. Neuroscience 2006;139:11071115 .

-21 Moult PR, Cross A, Santos SD, Carvalho AL, Lindsay Y, Connolly CN, Irving AJ, Leslie NR, Harvey J: Leptin regulates AMPA receptor trafficking via PTEN inhibition. J Neurosci 2010;30:4088-4101. 